\title{
Loss of L-PHA-, PNA-, or ConA-reactive oligosaccharides is associated with a poor prognosis in human Burkitt's lymphoma
}

\author{
OSAMU SUZUKI, YOSHIHIRO NOZAWA and MASAFUMI ABE
}

\author{
Department of Pathology, School of Medicine, Fukushima Medical University, Fukushima, Japan
}

Received November 15, 2006; Accepted December 28, 2006

\begin{abstract}
The expression of cell surface oligosaccharides is associated with various biological phenomena. To clarify the relationship between lectin binding and the survival of patients with Burkitt's lymphoma, tumor samples from nine patients with Burkitt's lymphoma were analyzed by lectin histochemistry. Kaplan-Meier analysis showed that survival is significantly shorter for patients with negative reactivity for lectins from Phaseolus vulgaris (L-PHA), Arachis hypogaea (PNA), or Canavalia ensiformis (ConA) than for those with positive reactivity for these lectins. Immunohistochemistry for $\mathrm{N}$-acetylglucosaminyltransferase $\mathrm{V}$, which synthesizes ß1,6-branched oligosaccharides such as L-PHA-reactive oligosaccharides, was positive in 8 of 9 patients, but there was no correlation between its expression and that of L-PHA-reactive oligosaccharides. Collectively, a loss of L-PHA-, PNA-, or ConA-reactive oligosaccharides is closely associated with a poor prognosis in patients with Burkitt's lymphoma.
\end{abstract}

\section{Introduction}

Cell surface $\mathrm{N}$-glycosylation of tumor cells affects various biological processes such as metastasis (1-4), carcinogenesis (5-7), prognosis (8), malignant potential (9-11), cell adhesion and invasion (12-14). Demetriou et al reported that Phaseolus vulgaris lectin (L-PHA)-reactive oligosaccharides synthesized by $\mathrm{N}$-acetylglucosaminyltransferase V (GnT-V) modify $\mathrm{T}$ cell receptor signaling by interacting with galectin-3, a galactose-specific lectin (15). In addition, inhibition of cell surface $\mathrm{N}$-glycosylation in $\alpha$-mannosidase II gene knockout mice is reported to be closely associated with development of autoimmune disease (16). These data suggest that L-PHAreactive oligosaccharides regulate $\mathrm{T}$ lymphocyte activation.

Previously, Dennis et al reported that L-PHA-reactive oligosaccharides regulate adhesion of murine $\mathrm{T}$ cell lymphoma

Correspondence to: Dr Osamu Suzuki, Fukushima Medical University, School of Medicine, Department of Pathology, 1 Hikarigaoka, Fukushima 960-1295, Japan

E-mail: osuzuki@fmu.ac.jp

Key words: oligosaccharides, Burkitt's lymphoma, prognosis cells to the extracellular matrix (ECM) and reduce their adhesion to fibronectin and collagen type IV (1). N-glycosylation also affects the adhesion of $\beta_{1}$ integrin to ECM (17). Furthermore, studies with the $\alpha$-mannosidase II inhibitor swainsonine show that cell surface $\mathrm{N}$-glycosylation closely correlates with tumor cell invasiveness on laminin-1 (13). These findings suggest that cell surface N-glycosylation is closely linked to the adhesion or invasion to ECM by tumor cells.

The expression of L-PHA-reactive oligosaccharides, which are $\mathrm{N}$-glycans, is closely associated with the clinical outcome of human diffuse large B cell lymphoma $(18,19)$, and a loss of L-PHA-reactive oligosaccharides corresponds with a poor prognosis in non-small cell lung cancer (20). In the present study, we report that a loss of cell surface reactivity for L-PHA, Arachis hypogaea lectin (PNA), or Canavalia ensiformis lectin (ConA) is closely associated with a poor prognosis in human Burkitt's lymphoma.

\section{Materials and methods}

Patients. Nine cases of Burkitt's lymphoma from the files of the First Department of Pathology, Fukushima Medical University were examined. In all cases, a diagnosis of Burkitt's lymphoma was made based on the WHO classification (21). The cases included five male and four female patients, with ages ranging from 4 to 42 years (median, 32). The survival time ranged from 2 to 24 months.

Reagents. Biotinylated lectins from Arachis hypogaea (PNA), Phaseolus vulgaris (L-PHA), Canavalia ensiformis (ConA), Maclura pomifera (MPA), Artocarpus integrifolia (AIA), Triticum vulgare (WGA), Ulex europaeus (UEA-1), and Glycine max (SBA) were purchased from EY Laboratories (San Mateo, CA, USA). The monoclonal antibody that recognizes GnT-V was kindly provided by Drs N. Taniguchi and E. Miyoshi (8).

Lectin staining. Formalin-fixed, paraffin-embedded sections of biopsy materials were prepared according to standard procedures. The paraffin-embedded sections were deparaffinized in xylene and rehydrated with a graded series of ethanol. After washing twice for $5 \mathrm{~min}$ in $0.01 \mathrm{M}$ phosphatebuffered saline, $\mathrm{pH} 7.4$ (PBS), the sections were incubated with $0.3 \%$ hydrogen peroxidase in methanol for $20 \mathrm{~min}$ at room temperature to eliminate the endogenous peroxidase activity. 
A

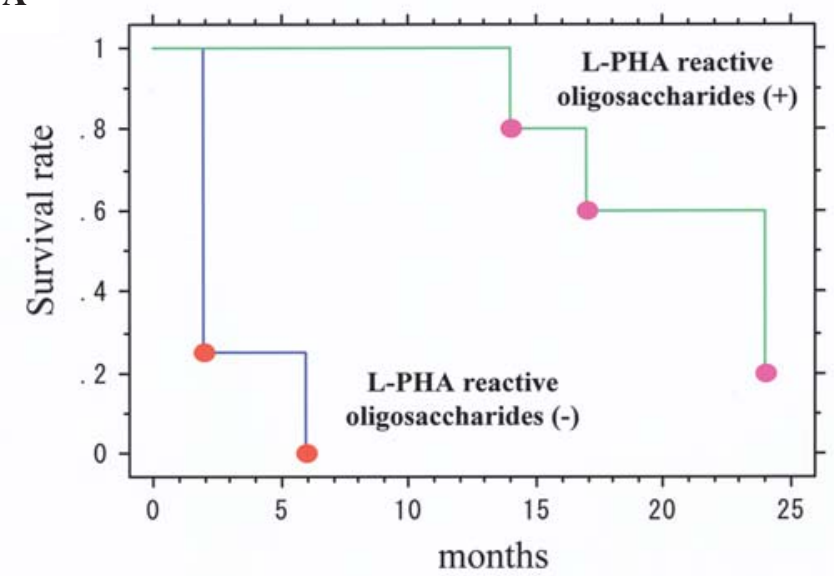

"

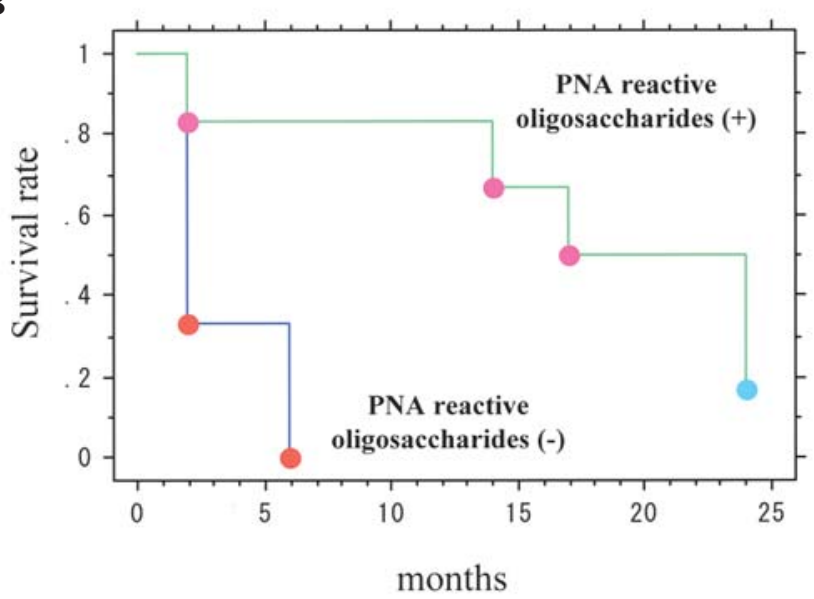

C

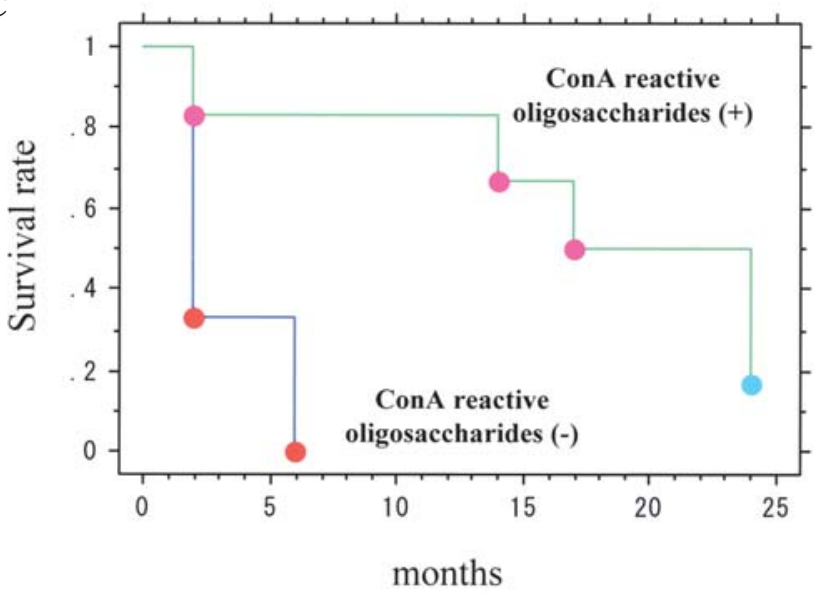

Figure 1. Relationship between survival and lectin binding to tumor samples from patients with Burkitt's lymphoma. The survival of patients negative for binding of L-PHA, PNA, or ConA was significantly shorter than that of patients positive for binding of these lectins. Survival curves were established according to the Kaplan-Meier method, and P-values were calculated based on Wilcoxon's test. The horizontal line represents months of survival, and the vertical line represents the survival rate. (A) $\mathrm{P}=0.0033$, L-PHA-positive cases vs. L-PHA-negative cases. (B) $\mathrm{P}=0.0271$, PNApositive cases vs. PNA-negative cases. (C) $\mathrm{P}=0.0271$, ConA-positive cases vs. ConA-negative cases.

To remove sialic acids from oligosaccharides, the sections were treated for $1 \mathrm{~h}$ at $37^{\circ} \mathrm{C}$ with 0.1 units $/ \mathrm{ml}$ neuraminidase from Vibrio cholerae (Roche, Tokyo, Japan) in sodium acetate

A

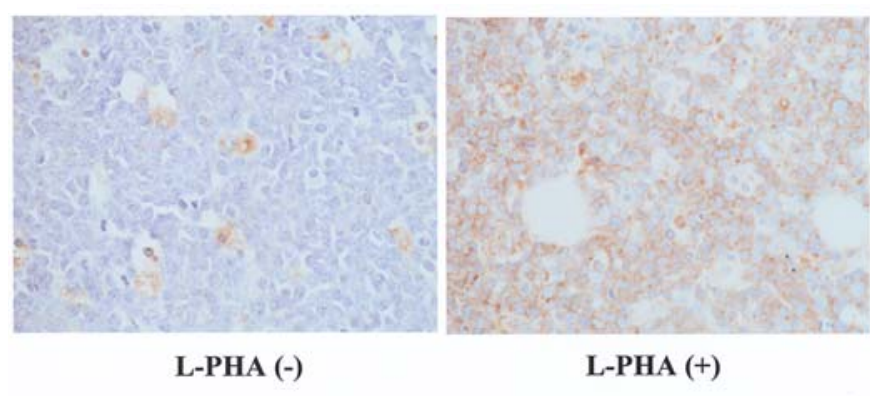

B

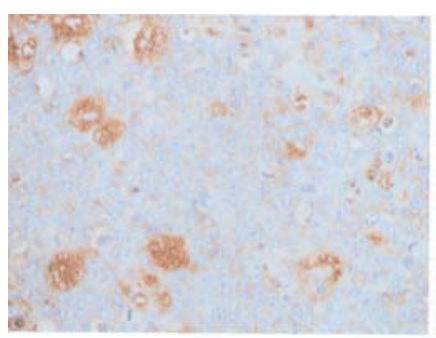

PNA (-)

C

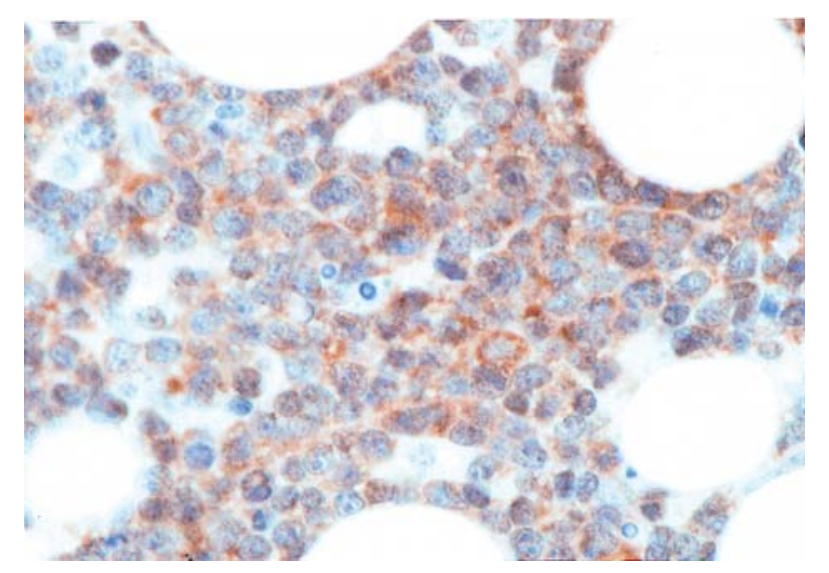

Figure 2. Staining for L-PHA or PNA-reactive oligosaccharides and immunohistochemical staining for GnT-V in Burkitt's lymphoma. (A) L-PHA-reactive glycoconjugates are expressed on the surface or in the cytoplasm of lymphoma cells. (B) PNA-reactive glycoconjugates are expressed on the surface of lymphoma cells. (C) GnT-V is found throughout the cytoplasm of lymphoma cells.

buffer ( $\mathrm{pH}$ 5.6) containing $0.04 \mathrm{M} \mathrm{CaCl}_{2}$ (20). Next, the sections were incubated with 5\% skim milk in PBS for 20 min at room temperature to reduce nonspecific staining. After washing 3 times for $5 \mathrm{~min}$ in $0.05 \mathrm{M}$ Tris ( $\mathrm{pH} 7.6$ ), the sections were incubated overnight at $4^{\circ} \mathrm{C}$ with biotinylated lectins at various concentrations, followed by $20 \mathrm{~min}$ at room temperature with streptavidin-biotin-peroxidase complex (Nichirei, Tokyo, Japan) and then $5 \mathrm{~min}$ in diaminobenzidine (DAB) $-\mathrm{H}_{2} \mathrm{O}_{2}$ solution (30 $\mu \mathrm{g}$ DAB in $0.05 \mathrm{M}$ Tris buffer). After each incubation step, the sections were washed 3 times for $5 \mathrm{~min}$ in PBS. Finally, the sections were counterstained with hematoxylin and mounted (Table I). 
Table I. Lectins used for histochemical staining.

\begin{tabular}{lcc}
\hline Lectins & Dilution & Carbohydrate specificity \\
\hline Arachis hypogaea (PNA) & $1: 300$ & $\beta$ Gal/GalNAc \\
Maclura pomifera (MPA) & $1: 300$ & $\alpha$ Gal/GalNAc \\
Artocarpus integrifolia (AIA) & $1: 500$ & \\
Glycine max (SBA) & $1: 300$ & $\alpha$ Man \\
Canavalia ensiformis (ConA) & $1: 200$ & $\beta$ GlcNAc/ $\alpha$ NeuAc \\
Triticum vulgare (WGA) & $1: 200$ & $\alpha$ Fuc \\
Ulexeuropaeus (UEA-1) & $1: 100$ & \\
Phaseolus vulgaris & & GlcNAc $\beta$ 1-6Man $\alpha$ 1-6R-Asn \\
leukoagglutinating lectin (L-PHA) & $1: 500$ & \\
\hline $\begin{array}{l}\text { Gal, galactose; GalNAc, N-acetylgalactosamine; Fuc, fucose; Man, mannose; GlcNAc, N-acetylglucosamine; NeuAc, N-acetylneuraminic } \\
\text { acid; Asn, aspartic acid. }\end{array}$ & & \\
\hline
\end{tabular}

Immunohistochemical staining for GnT-V. Paraffin-embedded sections were deparaffinized in xylene and rehydrated with a graded series of ethanol. After washing the sections twice for $5 \mathrm{~min}$ in $0.01 \mathrm{M} \mathrm{PBS}$, they were incubated for $20 \mathrm{~min}$ at room temperature with $0.3 \%$ hydrogen peroxidase in methanol to eliminate the endogenous peroxidase activity. After washing 3 times for $5 \mathrm{~min}$ in PBS, the sections were incubated overnight at $4^{\circ} \mathrm{C}$ with 1:1000 anti GnT-V monoclonal antibody, followed by 1:1000 biotinylated anti-mouse immunoglobulin antibody (Dako) for $20 \mathrm{~min}$ at room temperature and then for $20 \mathrm{~min}$ with avidin-biotin-peroxidase complex (Dako). Next, the sections were incubated for $5 \mathrm{~min}$ with $\mathrm{DAB}-\mathrm{H}_{2} \mathrm{O}_{2}$ solution (30 $\mu \mathrm{g}$ DAB in $0.05 \mathrm{M}$ Tris buffer). After each incubation step, the sections were washed 3 times for $5 \mathrm{~min}$ in PBS. The sections were counterstained with hematoxylin and mounted.

Evaluation of lectin-binding reactivity and immunohistochemical findings. All lectin- and immunohistochemically stained sections were examined using a light microscope. Lectin-binding reactivity and GnT-V expression was assessed as follows: negative, $<10 \%$ positive tumor cells; positive, $\geq 10 \%$ positive tumor cells.

\section{Results}

Expression of L-PHA-, PNA-, or ConA-reactive oligosaccharides and survival curves. We examined the binding of eight lectins to tumor samples from nine patients with Burkitt's lymphoma. We found that the survival of the patients that were negative for L-PHA, PNA, or ConA binding was significantly shorter than that of patients that were positive for the binding of these lectins (Fig. 1A-C). There was significant correlation between the reactivity for L-PHA, PNA, and Con $\mathrm{A}$ and prognosis $(\mathrm{P}=0.0033$ for $\mathrm{L}-\mathrm{PHA}$ binding and $\mathrm{P}=0.0271$ for PNA or ConA binding), but no significant correlation between the binding of other lectins (from MPA, AIA, WGA, UEA-1, and SBA) and prognosis.
Lectin staining. In lymphoma cells positive for L-PHA binding, the L-PHA-reactive oligosaccharides were expressed on the cell surface or in the cytoplasm. In all samples that were positive for PNA binding, PNA-reactive oligosaccharides were expressed on the surface of lymphoma cells (Fig. 2A and $\mathrm{B})$.

Expression of $G n T-V$. Of the 9 cases of Burkitt's lymphoma, lymphoma cells from 8 expressed GnT-V. Except in one of these cases, GnT-V was expressed in the cytoplasm (Fig. 2C). There was no significant correlation between the expression of L-PHA-reactive oligosaccharides and GnT-V expression.

\section{Discussion}

It has been reported that expression of L-PHA-reactive oligosaccharides is closely associated with distant metastasis of murine lymphoma (1). In contrast, we show herein that a lack of L-PHA-reactive oligosaccharides corresponds to a worse prognosis in Burkitt's lymphoma. Therefore, L-PHAreactive oligosaccharides may have different functions in human and mouse lymphomas.

$\mathrm{N}$-glycosylation on the cell surface is regulated by several glycosyltransferases including GnT-V, which synthesizes ß1,6-branched oligosaccharides such as L-PHA-reactive oligosaccharides. GnT-V is known to play important roles in metastasis $(3,4)$, carcinogenesis $(5-7)$, cell adhesion $(12,13)$ and invasion (14), and the expression patterns of GnT-Vsynthesized $\mathrm{N}$-glycans appear to correlate with the patient's clinical outcome $(19,20)$. Alteration in the activity of some glycosyltransferases that synthesize $\mathrm{N}$-glycans results in the remodeling of the $\mathrm{N}$-glycan structures on several glycoproteins, affecting their function (22). In the present study, however, we did not find a significant correlation between the expression of L-PHA reactive oligosaccharides and the expression of GnT-V. This suggests that the differences in the level of L-PHA-reactive oligosaccharides between the different 
patients is not due to altered expression of GnT-V but rather to changes in the expression of other enzymes that regulate $\mathrm{N}$-glycan biosynthesis. The production of $\beta 1,6$-branched oligosaccharides by GnT-V is reported to be regulated by the concentration of the donor, UDP-GlcNAc, as well as the level of GnT-V (23). Thus, the loss of L-PHA-reactive oligosaccharides may be due to a reduction in the amount of UDP-GlcNAc.

In the present study, we showed that ConA-reactive oligosaccharides were present in the cytoplasm of lymphoma cells. ConA reacts with mannose residues, such as high mannosetype N-linked oligosaccharides, which are synthesized in the Golgi and are precursors of mature complex-type N-linked oligosaccharides including L-PHA-reactive oligosaccharides (24). There is a tendency of a positive correlation between the binding of L-PHA and ConA, suggesting that the loss of L-PHA-reactive oligosaccharides may be due to a loss of precursors, such as ConA-reactive oligosaccharides, but not a loss of GnT-V.

$\mathrm{N}$-glycans such as L-PHA-reactive oligosaccharides are known to be ligands for galectin-1, and L-PHA-reactive oligosaccharides regulate cell death by interacting with galectin-1 $(25,26)$. Ligands of galectin-1 are known to be N-glycans of CD45 (27), and L-PHA reactive oligosaccharides are reported to be expressed on CD45 (28). It has been reported that Nglycans synthesized by GnT-V regulate cell adhesion to ECM $(29,30)$. Further investigations are needed to determine whether alteration of cell surface $\mathrm{N}$-glycans such as L-PHAreactive oligosaccharides modulate galectin-induced cell death or cell adhesion to ECM in Burkitt's lymphoma.

We have previously shown that loss of L-PHA reactive oligosaccharides is associated with a poor prognosis in human diffuse large B cell lymphoma (DLBCL) $(18,19)$. Although there is a slight difference in sialylation of the terminal residues of oligosaccharides, relationship between L-PHA reactive oligosaccharide expression and prognosis in DLBCL is correlated to that in Burkitt's lymphoma in the present study. These data suggest that L-PHA reactive oligosaccharides may play important and common roles in malignant behavior in both types of lymphoma.

The current results suggested that a loss of PNA-reactive oligosaccharides is associated with a poor prognosis in human Burkitt's lymphoma. PNA is known to react with O-glycans or glycolipids, and cell surface O-glycans have been shown to regulate galectin-1-induced cell death in human B cell lymphoma (26). Therefore, further studies should examine whether a loss of PNA-reactive oligosaccharides prevents galectin-1-induced cell death in Burkitt's lymphoma. PNA reactive O-glycans are known to be linked to CD45 (31), and these O-glycans of CD45 regulate homodimerization and phosphatase activity of CD45 isoforms (32). Therefore, further study is needed to clarify whether alteration of CD45 Oglycans modulate functional activity of phosphatase of CD45 in human B cell lymphoma.

\section{Acknowledgements}

We would like to thank Ms. M. Satoh and Mrs. H. Kaneko for their technical assistance, and we are grateful to Drs N. Taniguchi and E. Miyoshi (Osaka University Faculty of
Medicine, School of Allied Health Science, Department of Biochemistry) for the monoclonal antibody for GnT-V.

\section{References}

1. Dennis JW, Laferte S, Waghorne C, Breitman ML and Kerbel RS: Beta 1-6 branching of Asn-linked oligosaccharides is directly associated with metastasis. Science 236: 582-585, 1987.

2. Pierce M, Buckhaults P, Chen L and Fregien N: Regulation of $\mathrm{N}$-acetylglucosaminyltransferase $\mathrm{V}$ and Asn-linked oligosaccharide $B(1,6)$ branching by a growth factor signaling pathway and effects on cell adhesion and metastatic potential. Glycoconj J 14: 623-630, 1997.

3. Shao DM, Wang QH, Chen C, Shen ZH, Yao M, Zhou XD, Tang ZY and Gu JX: N-acetylglucosaminyltransferase V activity in metastatic models of human hepatocellular carcinoma in nude mice. J Exp Clin Cancer Res 18: 331-335, 1999.

4. Guo Hua-Bei, Zhang QS and Chen H: Effects of H-ras and v-sis overexpression on $\mathrm{N}$-acetylglucosaminyltransferase $\mathrm{V}$ and metastasis-related phenotypes in human hepatocarcinoma cells. J Cancer Res Clin Oncol 126: 263-270, 2000.

5. Kang R, Saito H, Ihara Y, Miyoshi E, Koyama N, Sheng Y and Taniguchi N: Transcriptional regulation of the N-acetylglucosaminyltransferase $\mathrm{V}$ gene in human bile duct carcinoma cells (HuCC-T1) is mediated by Ets-1. J Biol Chem 271: 26706-26712, 1996.

6. Ko JH, Miyoshi E, Noda K, Ekuni A, Kang R, Ikeda Y and Taniguchi N: Regulation of the GnT-V promoter by transcription factor Ets-1 in various cancer cell lines. J Biol Chem 274: 22941-22948, 1999

7. Miyoshi E, Nishikawa A, Ihara Y, Gu J, Sugiyama T, Hayashi N, Fusamoto H, Kamada T and Taniguchi N: N-acetylglucosaminyltransferase III and V messenger RNA levels in LEC rats during hepatocarcinogenesis. Cancer Res 53: 3899-3902, 1993.

8. Murata K, Miyoshi E, Kameyama M, Ishikawa O, Kabuto T, Sasaki Y, Hiratsuka M, Ohigashi H, Ishiguro S, Ito S, Honda H, Takemura F, Taniguchi N and Imaoka S: Expression of N-acetylglucosaminyltransferase $\mathrm{V}$ in colorectal cancer correlates with metastasis and poor prognosis. Clin Cancer Res 6: 1772-1777, 2000.

9. Fernandes B, Sagman M, Auger M, Demetrio M and Dennis JW: B1-6 branched oligosaccharides as a marker of tumor progression in human breast and colon neoplasia. Cancer Res 51: 718-723, 1991.

10. Yao M, Zhou DP, Jiang SM, Wang QH, Zhou XD, Tang ZY and Gu JX: Elevated activity of $\mathrm{N}$-acetylglucosaminyltransferase V in human hepatocellular carcinoma. J Cancer Res Clin Oncol 124: 27-30, 1998.

11. Nan BC, Shao DM, Chen HL, Huang Y, Gu JX, Zhang YB and Wu ZG: Alteration of N-acetylglucosaminyltransferases in pancreatic carcinoma. Glycoconj J 15: 1033-1037, 1998.

12. Mingzhe Z, Fang H and Hakomori S: Functional role of N-glycosylation in $\alpha 5 \beta 1$ integrin receptor de-N-glycosylation induces dissociation or altered association of $\alpha 5$ and $\beta 1$ subunits and concomitant loss of fibronectin binding activity. J Biol Chem 269: 12325-12331, 1994.

13. Jasiulionis MG, Chammas R, Ventura AM, Travassos LR and Brentani RR: $\alpha 6 \beta 1$-integrin, a major cell surface carrier of $\beta 1,6-$ branched oligosaccharides, mediates migration of EJ-rastransformed fibroblasts on Laminin-1 independently of its glycosylation state. Cancer Res 56: 1682-1689, 1996

14. Yamamoto H, Swoger J, Greene S, Saito T, Hurh J, Sweely C, Leestma J, Mkrdichian E, Cerullo L, Nishikawa A, Ihara Y, Taniguchi N and Moskal JR: $B 1,6-\mathrm{N}$-acetylglucosamine-bearing $\mathrm{N}$-glycans in human gliomas: implications for a role in regulating invasivity. Cancer Res 60: 134-142, 2000.

15. Demetriou M, Granovsky M, Quaggin S and Dennis JW: Negative regulation of T-cell activation and autoimmunity by Mgat5 N-glycosylation. Nature 409: 733-739, 2001.

16. Chui D, Sellakumar G, Green R, Sutton-Smith M, McQuistan T, Marek K, Morris H, Dell A and Marth J: Genetic remodeling of protein glycosylation in vivo induces autoimmune disease. Proc Natl Acad Sci USA 98: 1142-1147, 2001.

17. Zheng M, Fang H and Hakomori S: Functional role of N-glycosylation in $\alpha 5 \beta 1$ integrin receptor. J Biol Chem 269: 12325-12331, 1994. 
18. Suzuki O, Nozawa Y, Kawaguchi T and Abe M: Phaseolus vulgaris leukoagglutinationg lectin-binding reactivity in human diffuse large B cell lymphoma and its relevance to the patient's clinical outcome: lectin histochemistry and lectin blot analysis. Pathol Int 49: 874-880, 1999.

19. Suzuki O, Nozawa Y, Kawaguchi T and Abe M: Alpha-2,6sialylation of L-PHA reactive oligosaccharides and expression of N-acetylglucosaminyltransferase $\mathrm{V}$ in human diffuse large B cell lymphoma. Oncol Rep 10: 1759-1764, 2003.

20. Akita DH, Miyoshi E, Suzuki O, Itoh T, Katoh H and Taniguchi N: Expression of $\mathrm{N}$-acetylglucosaminyltransferase $\mathrm{V}$ is associated with prognosis and histology in non-small cell lung cancers. Clin Cancer Res 10: 1773-1779, 2004.

21. Jaffe ES, Harris NL, Stein H and Vardiman JW: Tumors of hematopoietic and lymphoid tissues. World Health Organization Classification of Tumors. IARC press, 2001

22. Rebbaa A, Yamamoto H, Moskal JR and Bremer EG: Binding of erythroagglutinating phytohemagglutinin lectin from Phaseolus vulgaris to the epidermal growth factor receptor inhibits receptor function in the human glioma cell line, U373 MG. J Neurochem 67: 2265-2272, 1996.

23. Sasai K, Ikeda Y, Fujii T, Tsuda T and Taniguchi N: UDPGlcNAc concentration is an important factor in the biosynthesis of beta1,6-branched oligosaccharides: regulation based on the kinetic properties of $\mathrm{N}$-acetylglucosaminyltransferase $\mathrm{V}$. Glycobiology 12: 119-127, 2002.

24. Hubbard SC and Ivatt RJ: Synthesis and processing of asparagines-linked oligosaccharides. Ann Rev Biochem 50: 555-583, 1981.

25. Suzuki O, Nozawa Y and Abe M: Altered N-glycosylation in CD45 and regulatory roles of altered $\mathrm{N}$-glycosylation in galectin-1-induced growth inhibition in human diffuse large B cell lymphoma. Oncol Rep 13: 109-114, 2004.
26. Suzuki O, Nozawa Y and Abe M: Regulatory roles of altered $\mathrm{N}$ - and O-glycosylation of CD45 in galectin-1-induced cell death in human diffuse large B cell lymphoma. Int J Oncol 26: 1063-1068, 2005.

27. Perillo NL, Pace KE, Seilhamer JJ and Baum LG: Apoptosis of T cells mediated by galectin-1. Nature 378: 736-739, 1995

28. Monostori E, Hartyani Z, Hegedus Z, Ocsovszky I, Pallinger E and Ando I: Microheterogeneity of the cell surface tyrosine phosphatase, CD45RA, on T cells: phytohemagglutinin binding and non-binding fraction of the $220 \mathrm{kDa}$ isoform. Immunol Lett 59: 171-176, 1997.

29. Guo HB, Lee I, Kamar M, Akiyama SK and Pierce M: Aberrant $\mathrm{N}$-glycosylation of betal integrin causes reduced alpha5beta 1 integrin clustering and stimulates cell migration. Cancer Res 62: 6837-6845, 2002 .

30. Zhang Y, Zhao JH, Zhang XY, Guo HB, Liu F and Chen HL: Relations of the type and branch of surface N-glycans to cell adhesion, migration and integrin expressions. Mol Cell Biochem 260: 137-146, 2004

31. Amado M, Yan Q, Comelli EM, Collins BE and Paulson JC: Peanut agglutinin high phenotype of activated $\mathrm{CD}^{+} \mathrm{T}$ cells results from de novo synthesis of CD45 glycans. J Biol Chem 279: 36689-36697, 2004

32. Zheng Xu and Arther W: Negative regulation of CD45 by differential homodimerization of the alternatively spliced isoforms. Nat Immun 3: 764-771, 2002. 